http://jmscr.igmpublication.org/home/ ISSN (e)-2347-176x ISSN (p) 2455-0450

crossref DOI: https://dx.doi.org/10.18535/jmscr/v8i10.45

\title{
Relative Adrenal Insufficiency as a Predictive Factor of Development of Decompensation in Cirrhotic Ascites
}

\author{
Authors \\ Anvin Thomas ${ }^{1}$, R. Murali ${ }^{2}$, K Prem Kumar ${ }^{3}$ \\ Institute of Medical Gastroenterology, Madras Medical College, The Tamil Nadu Dr. M.G.R Medical \\ University, Chennai, India
}

\begin{abstract}
Introduction: Relative adrenal insufficiency is a feature of liver dysfunction where adrenal cortex cannot synthesize enough cortisol at times of pathological stress and which may not manifest during normal periods.

Aim: To assess the prevalence of Relative Adrenal Insufficiency (RAI) in stable cirrhotic ascites and its relationship with further occurrence of infective and non-infective complications.

Methodology: In this prospective study, out of all cirrhotic patients presenting with ascites to our department, those with SBP, HRS, jaundice, sepsis, ARDS, previous steroid use, other complications/ comorbidities were excluded at the time of admission and 60 patients were selected. In these patients LDSST was done and RAI was diagnosed on the basis of low post stimulation cortisol and low delta cortisol. These 60 patients were divided into two cohorts, those with RAI and those without RAI and followed up over a period of 6 months for the development of infective (SBP, HRS, Sepsis) and non-infective complications (encephalopathy, coagulopathy, jaundice, bleeding) to know whether the two groups had any significant difference in the occurrence of these complications.

Results: Infective complications like SBP (63\%;p value 0.018),HRS(55.6 \%;p value 0.017), Sepsis (44 \%,p value 0.046) were significantly increased in RAI group. With respect to non-infective complications and other infections there were no significant differences.

Conclusion: In those patients with RAI selective interventions like corticosteroids or albumin could be tried to prevent infective complications.

Keywords: RAI-Relative Adrenal Insufficiency, SBP - spontaneous bacterial peritonitis, HRS- hepatorenal syndrome.
\end{abstract}

\section{Introduction}

Hepatoadrenal syndrome, and relative adrenal insufficiency (RAI) are relatively newer entities in the rapidly developing field of clinical hepatology. It is known that cholesterol especially HDL is needed for the synthesis of adrenal cortical hormones. In cirrhosis there is profound deficiency of lipid parameters like total cholesterol, LDL and $\mathrm{HDL}^{[1-3]}$. The adrenal cortex in cirrhotics cannot synthesize adequate cortisol especially at times of physiological or pathological stress leading to relative adrenal insufficiency (RAI) or "adrenal exhaustion syndrome" which may not manifest during normal periods ${ }^{[4,5]}$.

More over cirrhosis is a pro-inflammatory state characterized by cytokinemia including tumor necrosis factor (TNF- $\alpha$ ), interleukelin-6 (IL-6), IL-1 
and lipopolysaccharide endotoxinemia ${ }^{[6,7]}$, which has detrimental effect on HPA axis. Other mechanisms involved are 1)TNF $\alpha$ decreases the secretion of ACTH from pituitary by competing with CRH (Corticotropin releasing hormone)2) cytokinemia contributes to decreased HDL by inhibiting the apolipoprotein A1 synthesis resulting in decreased substrate delivery to adrenal glands ${ }^{[7]}$. 3) coagulopathy associated with cirrhosis could lead to adrenal hemorrhage precipitating adrenal insufficiency ${ }^{[8]}$.

However most of these studies about RAI are in decompensated chronic liver disease[9]or in cirrhotic patients with sepsis and there are only limited studies assessing the prevalence of relative adrenal insufficiency in stable cirrhotics and its relation to occurrence of infective and noninfective complications.

Hence we conducted this study to assess the prevalence of RAI in stable cirrhoticsand its relation to further decompensation

\section{Aims and Objectives}

To assess the prevalence of relative adrenal insufficiency (RAI ) in cirrhotic ascites and its relationship with further decompensation and occurrence of complications.

\section{Methodology}

In this prospective study 122 cirrhotic patients presenting with ascites to our medical gastroenterology department from September 2018 to september2019 were identified on the basis of clinical, laboratory parameters, and imaging. Baseline CBC,PT- INR, LFT, RFT, USG abdomen, Portal vein Doppler, Ascitic fluid study, cultures, Serum Procalcitonin were done within 24 hours of admission. All patients with SBP, other infections, hepatic encephalopathy, HRS, jaundice, overt gi bleed, previous adrenal /pituitary disease, severe heart disease, COPD, previous steroid use, overt and occult sepsis (procalcitonin $>0.5 \mathrm{ng} / \mathrm{ml}$ or positive cultures), hypotension, ards , anemia (hb $<10)$ and severe hypoalbuminemia $(<2.5 \mathrm{mg} / \mathrm{dl})$ at the time of presentation were excluded from the study. In the end 60 patients with mild to moderate ascites without any other decompensation or infection were included in the study.

Relative adrenal sufficiency (RAI) was diagnosed on the basis of Low Dose Short Synacthen test (LDSST) in which baseline total cortisol (measured at 9:30 am - due to delayed peak in cirrhosis) and plasma cortisol measured 30 minutes after stimulation with $1 \mu \mathrm{g}$ corticotrophinare measured. If post stimulation (30 $\mathrm{min}$ ) cortisol is less than 500 $\mathrm{nmol} / \mathrm{L}$ and delta cortisol level (difference between post stimulation cortisol level and baseline cortisol) less than $250 \mathrm{nmol} / \mathrm{L}$ is considered diagnostic of Relative adrenal insufficiency(RAI).

Out of the 60 patients the patients with RAI and those without RAI were separately followed up over a period of 6 months for the development of ascites, hyponatremia, spontaneous bacterial peritonitis (SBP), hepatorenal syndrome (HRS), jaundice, severe sepsis, bleeding and hepatic encephalopathy to know whether there are any significant differences in the rate, type and severity of various decompensations in the two groups. HRS, SBP, encephalopathy, coagulopathy, were defined on the basis of latest EASL guidelines for decompensated cirrhosis $^{[17]}$ and sepsis on the basis of surviving sepsis guidelines ${ }^{[18]}$

\section{Statistical Analysis}

Data was entered in Microsoft Excel and analysis done using IBM SPSS software. Percentage analysis was done for categorical variables like age, sex, aetiology etc .Mean with standard deviation was used for continuous variables like albumin, sodium, and MELD scores. Categorical variables were analysed using Chi - square test and quantitative data using independent $\mathrm{T}$ test. A $\mathrm{p}$ value of less than 0.05 was considered to be statistically significant with $95 \%$ confidence interval .

\section{Results}

Of the 60 patients with cirrhotic ascites RAI was found in 27(45\%) patients and 33patients had no RAI. There were no significant differences in the baseline characteristics including age, sex , aetiology 
of liver disease, MELD and CTP scores between the two groups except for the serum sodium.

Table 1: Demographic/Gender/baseline laboratory analysis

\begin{tabular}{|c|c|c|c|c|c|c|}
\hline & & & $\begin{array}{l}\text { RAS } \\
\text { Present }\end{array}$ & $\begin{array}{c}\text { RAS } \\
\text { Absent }\end{array}$ & $\begin{array}{l}\text { TEST } \\
\end{array}$ & $\begin{array}{l}\text { SIGNIFI } \\
\text { CANCE }\end{array}$ \\
\hline $\begin{array}{l}\text { Mean A } \\
\text { SD) }\end{array}$ & e (MEAN & $+/-$ & $\begin{array}{c}55.477+/- \\
4.79\end{array}$ & $\begin{array}{c}54.73+/- \\
6.14\end{array}$ & T TEST & $\begin{array}{l}0.62 \\
(\mathrm{NS})\end{array}$ \\
\hline \multirow[t]{4}{*}{ Sex } & \multirow[t]{2}{*}{ Male } & $\overline{\mathrm{N}}$ & 24 & 29 & \multirow{4}{*}{$\begin{array}{c}\text { CHI } \\
\text { SQUA } \\
\text { RE }\end{array}$} & \multirow[t]{2}{*}{$1.0(\mathrm{NS})$} \\
\hline & & $\%$ & 45.3 & 54.7 & & \\
\hline & \multirow[t]{2}{*}{ Female } & $\mathrm{N}$ & 3 & 4 & & \multirow{2}{*}{0.9 (NS) } \\
\hline & & $\%$ & 42.9 & 57.1 & & \\
\hline \multirow{6}{*}{$\begin{array}{l}\text { Aetiolo } \\
\text { gy }\end{array}$} & \multirow[t]{2}{*}{ Alcoholic } & $\bar{N}$ & $\overline{15}$ & $\overline{18}$ & \multirow{6}{*}{$\begin{array}{c}\text { CHI } \\
\text { SQUA } \\
\text { RE }\end{array}$} & \multirow[t]{2}{*}{$0.71(\mathrm{NS})$} \\
\hline & & $\%$ & 45.5 & 54.5 & & \\
\hline & \multirow[t]{2}{*}{ Viral } & $\mathrm{N}$ & 7 & 11 & & \multirow[t]{2}{*}{$0.75(\mathrm{NS})$} \\
\hline & & $\%$ & 38.9 & 61.1 & & \\
\hline & \multirow[t]{2}{*}{ Nafld } & $\mathrm{N}$ & 5 & 4 & & \multirow[t]{2}{*}{$0.83(\mathrm{NS})$} \\
\hline & & $\%$ & 55.6 & 44.4 & & \\
\hline \multicolumn{3}{|c|}{$\begin{array}{l}\text { Mean albumin level } \\
(\mathrm{MEAN+/-SD)}\end{array}$} & $\begin{array}{c}2.667+/- \\
0.61\end{array}$ & $\begin{array}{c}2.587+/- \\
0.67\end{array}$ & T TEST & $\overline{0.33(\mathrm{NS})}$ \\
\hline \multicolumn{3}{|c|}{$\begin{array}{l}\text { Sodium } \\
\text { (MEAN +/-SD) }\end{array}$} & $\begin{array}{c}128.52+/- \\
3.82\end{array}$ & $\begin{array}{c}134.33+ \\
/-2.33\end{array}$ & $\overline{T \text { T TEST }}$ & $\begin{array}{c}0.02(\mathrm{SIG} \\
)\end{array}$ \\
\hline \multicolumn{3}{|c|}{$\begin{array}{l}\text { CTPSCORE(MEAN+/- } \\
\text { SD) }\end{array}$} & $\begin{array}{c}8.33+/- \\
0.56\end{array}$ & $\begin{array}{l}8.42+/- \\
0.63\end{array}$ & $\overline{T \text { T TEST }}$ & $\overline{0.76(\mathrm{NS})}$ \\
\hline \multicolumn{3}{|c|}{$\begin{array}{l}\text { MELD SCORE(MEAN+/- } \\
\text { SD) }\end{array}$} & $\begin{array}{l}8.85+/- \\
1.09\end{array}$ & $\begin{array}{c}8.61+/- \\
1.31\end{array}$ & T TEST & $\overline{0.78(\mathrm{NS})}$ \\
\hline
\end{tabular}

There was no significant difference in the mean albumin level between the two groups

Mean sodium level was found to be significantly low in the RAI group.

Table 2: RAI and its Relation with Cirrhotic Complications(infective)

\begin{tabular}{|l|c|c|c|c|c|c|c|c|}
\hline \multirow{2}{*}{ Complication } & \multicolumn{2}{|c|}{ SBP } & \multicolumn{2}{c|}{ HRS } & \multicolumn{2}{c|}{ Sepsis } & \multicolumn{2}{c|}{$\begin{array}{l}\text { Infection } \\
\text { (other) }\end{array}$} \\
\cline { 2 - 10 } & $\mathrm{N}$ & $\%$ & $\mathrm{~N}$ & $\%$ & $\mathrm{~N}$ & $\%$ & $\mathrm{~N}$ & $\%$ \\
\hline $\begin{array}{l}\text { RAI } \\
\text { (Present) }\end{array}$ & 17 & 63 & 15 & 55.6 & 12 & 44.4 & 10 & 37 \\
\hline RAI (absent) & 10 & 30.3 & 8 & 24.2 & 6 & 18.2 & 8 & 24.2 \\
\hline Test & \multicolumn{6}{|c|}{ CHI SQUARE TEST } \\
\hline $\begin{array}{l}\text { Significance } \\
\text { (P value) }\end{array}$ & $0.018($ sig) & $0.017($ sig) & $0.046($ sig) & $0.397(\mathrm{NS})$ \\
\hline
\end{tabular}

Patients with relative adrenal insufficiency (RAI) had significantly higher occurrence of spontaneous bacterial peritonitis (SBP) (63\%,p value 0.018), hepatorenal syndrome (HRS) (55.6\%, p value 0.017), sepsis (44.4 \%, p vaue:0.046) but with regard to other infections there were no significant differences between those with RAI and those without RAI. Both absolute number and percentage analysis showed significant differences in the occurrence of SBP, HRS, Sepsis between the two groups
Table 3: Other Cirrhotic Complications (Non infective)

\begin{tabular}{|c|c|c|c|c|c|c|c|c|}
\hline \multirow[t]{2}{*}{ Complication } & \multicolumn{2}{|c|}{$\begin{array}{c}\text { Hepatic } \\
\text { Encephalopath } \\
\text { y }\end{array}$} & \multicolumn{2}{|c|}{$\begin{array}{c}\text { Coagulopath } \\
y\end{array}$} & \multicolumn{2}{|c|}{ Bleeding } & \multicolumn{2}{|c|}{ Jaundice } \\
\hline & $\mathrm{N}$ & $\%$ & $\mathrm{~N}$ & $\%$ & $\mathrm{~N}$ & $\%$ & $\mathrm{~N}$ & $\%$ \\
\hline RAI(Present) & 6 & 22 & 3 & 11.1 & 4 & 14.8 & 8 & 29.6 \\
\hline RAI(Absent) & 14 & 42.4 & 4 & 12.1 & 8 & 24.2 & 10 & 30.3 \\
\hline Test & \multicolumn{8}{|c|}{ CHI SQUARE TEST } \\
\hline $\begin{array}{l}\text { Significance } \\
\text { (P value) }\end{array}$ & \multicolumn{2}{|c|}{$0.168(\mathrm{NS})$} & \multicolumn{2}{|c|}{$1.0(\mathrm{NS})$} & \multicolumn{2}{|c|}{$0.519(\mathrm{NS})$} & \multicolumn{2}{|c|}{$1.0(\mathrm{NS})$} \\
\hline
\end{tabular}

With respect to development of other complications like hepatic encephalopathy, coagulopathy, bleeding and jaundice there were no significant differences between those with RAI and those without RAI as evident from the $\mathrm{p}$ values.

Table 4: Time to Development of first complication

\begin{tabular}{|l|c|c|c|c|}
\hline \multirow{2}{*}{$\begin{array}{l}\text { Time To First } \\
\text { Complication }\end{array}$} & \multicolumn{2}{|c|}{$<3$ months } & \multicolumn{2}{c|}{$>3$ months } \\
\cline { 2 - 5 } & $\mathrm{N}$ & $\%$ & $\mathrm{~N}$ & $\%$ \\
\hline RAI (present) & 18 & 56.7 & 9 & 33.3 \\
\hline RAI (absent) & 13 & 39.4 & 20 & 60.6 \\
\hline Test & \multicolumn{4}{|c|}{ CHI SQUARE TEST } \\
\hline Significance(P value) & \multicolumn{4}{|c|}{$042($ sig) } \\
\hline
\end{tabular}

In those patients with RAI , $56.7 \%$ had their first complication within a span of 3 months while $60.6 \%$ of those without RAI developed their first complication after 3 months .The inference being significantly early occurrence of complications in those with RAI ( $p$ value 0.042 ).

\section{Complications vs RAI}

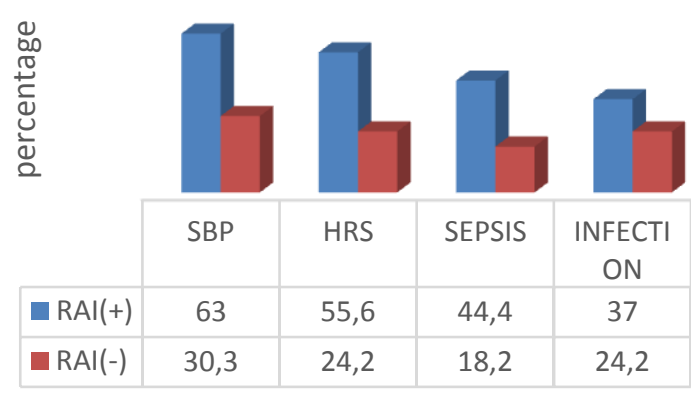

Fig 1: Bar Chart Showing Percentage of Significant Complications in Two Groups

\section{Discussion}

Although many studies have evaluated the presence of RAI in both compensated and decompensated 
cirrhosis and its correlation with development of further decompensation, this is the one of the few studies in which only cirrhotic patients with index decompensation as ascites were exclusively selected with the exclusion of all other types of presentations/comorbidities including occult sepsis and further divided into two cohorts; those with RAI and those without RAI and followed up for the development of both infective and non-infective cirrhotic complications.

Both the low dose short synacthen test (LDSSTwhere $1 \mu \mathrm{g}$ corticotrophin is used) and low delta cortisol (methodology) were used for diagnosis. This is based on the fact that a recent metaanalysis $^{[10]}$ showed LDSST is a more sensitive indicator of adrenal function in cirrhotic patients . Basal cortisol in our study was measured at $9: 30$ am rather than $8 \mathrm{am}$ because in cirrhotic patients there seems to be altered circadian rhythm of cortisol with delayed peak concentration. ${ }^{[11]}$

Only patients with $\mathrm{S}$ albumin level less than 2.5 $\mathrm{mg} / \mathrm{dl}$ were included in our study inorder to avoid the discrepancy associated with measurement of cortisol due to hypoalbuminemia. ${ }^{[12]}$

Significantly lower levels of sodium were seen in patients with RAI at baseline may be due to decreased sodium reabsorption in distal tubule in adrenal insufficiency or due to hypotonic suppression of thermostat for AVP release in adrenal deficiency. Non osmotic release of AVP is an important compensatory mechanism for systemic vasodilation in cirrhosis ${ }^{[13]}$.

Prevalence of RAI in our study was $45 \%$ which is slightly higher than in a similar study by fede et al [2] in stable cirrhotics probably because of slightly different cohort of patients in our study due to the stringent exclusion criteria . Serum Procalcitonin, cultures, LFT and RFT were done at baseline for all our patients so as to exclude other possible precipitants of adrenal insufficiency most common of which is sepsis. Adrenal insufficiency is common in all sorts of infections (most common being tuberculosis), autoimmune conditions, secondary vasculitis etc most of which could be excluded in view of the strict exclusion criteria.
On follow up of patients, those patients with RAI had significantly increased occurrence of SBP, HRS and sepsis diagnosed on the basis of latest EASL guidelines for decompensated cirrhosis and surviving sepsis guidelines respectively. Serum cortisol has significant role in vascular homeostasis ${ }^{[14]}$. In adrenal dysfunction there is significant reduction in the augmentation of vascular effect of RAAS and sympathetic nervous system by cortisol thereby causing a compensatory increase in the adrenergic tone which not only inhibits intestinal motility leading to bacterial overgrowth but also has immunosuppressive action leading to decreased chemotaxis of neutrophils and translocation of macrophages ${ }^{(14,15)}$. The ultimate result of this is translocation of bacteria into submucosal lymphatics and then in to systemic circulation leading to SBP, HRS and sepsis. But other infective complications like pneumonia, UTI, cellulitis were not significantly increased in those with RAI probably due to different portals of entry and mechanisms involved in these infections.

Non-infective complications like encephalopathy coagulopathy, jaundice and bleeding were not significantly increased in our study. All this complications are either portal hypertension related (bleeding), portosystemic shunting related(hepatic encephalopathy) or liver cell failure related (jaundice) indicating either the small number of study subjects or the fact that adrenal sufficiency has no significant effect on already established portal hypertension or portosystemic shunting.

In RAI group patients had a relatively earlier onset of complications $<3$ months in $66.7 \%$ as compared to $39.4 \%$ in non RAI group probably indicating the increased inflammatory milieu and detrimental effect of hypocortisolism on the already attenuated immunity in cirrhosis(cirrhosis associated immune dysfunction syndrome- CAIDS) predisposing to earlier occurrence of infections ${ }^{[16]}$

\section{Conclusion}

From our study a selective cohort of patients with relative adrenal insufficiency without overt/occult sepsis or complications other than ascites could be 
identified and higher occurrence of infective complications like SBP, HRS and sepsis were noted in the same group on follow up. In these patients selective interventions like corticosteroids or iv albumin could be tried (for supplementing the vascular tone, augmenting immune response and preventing the gut bacterial translocations) so as to prevent SBP and HRS respectively .Moreover our study emphasized the use of LDSST and delayed measurement of basal cortisol so as to increase the sensitivity of the detecting RAI. Our study is limited by small study sample so further studies with large sample size are needed to validate the above findings.

\section{References}

1. Thevenot T, Borot S, Remy-Martin A, Sapin R, Cervoni JP, in cirrhotic patients using concentration of serum-free and salivary cortisol. Liver Int 2011; 31: 425-433 [PMID: $21281437 \quad$ DOI: $\quad 10.1111 /$ j.14783231.2010.02431.x]

2. Fede G, Spadaro L, Tomaselli T, Privitera G. Assessment of adrenocortical reserve in stable patients with cirrhosis. J Hepatol 2011; 54: 243-250 [PMID: 21056503 DOI: 10.1016/j.jhep.2010.06.034]

3. Tan T, Chang L, Woodward A, McWhinney B, Galligan JCharacterising adrenal function using directly measured plasma free cortisol in stable severe liver disease. J Hepatol 2010; 53: 841848 [PMID: 20739086 DOI: 10.1016/j.jhep.2010.05.020]

4. Gui D, Spada PL, De Gaetano A, Pacelli F. Hypocholesterolemia and risk of death in the critically ill surgical patient. Intensive Care Med 1996; 22: 790-794 [PMID: 8880248 DOI: 10.1007/ BF01709522]

5. Marik PE. Adrenal-exhaustion syndrome in patients with liver disease. Intensive Care Med 2006; 32: 275-280 [PMID: 16432671 DOI: 10.1007/s00134-005-0005-5]

6. Soares JB, Pimentel-Nunes $\mathrm{P}$, The role of lipopolysaccharide/toll-like receptor 4 signaling in chronic liver diseases. Hepatol Int 2010; 4:
659-672[PMID:21286336

DOI:10.1007/s12072-010-9219-x]

7. Sekiyama KD, Yoshiba M,. Circulating proinflammatory cytokines (IL-1 beta, TNFalpha, and IL-6) and IL-1 receptor antagonist (IL-1Ra) in fulminant hepatic failure and acute hepatitis. Clin Exp Immunol 1994; 98: 71-77 [PMID: 7923888]

8. Marik PE. Adrenal-exhaustion syndrome in patients with liver disease. Intensive Care Med 2006; 32: 275-280 [PMID: 16432671 DOI: 10.1007/s00134-005-0005-5]

9. Hebbar KB, Stockwell JA, Leong T, Fortenberry JD. Incidence of adrenal insufficiency and impact of corticosteroid supplementation in critically ill children with systemic inflammatory syndrome. Crit Care Med 2011; 39: 1145-1150 [PMID: 21336126 DOI: 10.1097/CCM.0b013e31820eb4e4]

10. Montagnese S, Middleton B, Mani AR, Skene DJ, Morgan MY. Hepatoadrenal syndrome: doesdoes cortisol sample time matter? J Hepatol. 2009;50(84):206

11. Kazlauskaite R, Evans AT, Consortium for Evaluation of Corticotropin Test in Hypothalamic-Pituitary Adrenal Insufficiency. Corticotropin tests for hypothalamicpituitary-adrenal insufficiency: a metaanalysis. J Clin Endocrinol Metab. 2008;93:4245-4253

12. Coolens JL, Van Baelen H, Heyns W. Clinical use of unbound plasma cortisol as calculated from total cortisol and corticosteroid-binding globulin. J Steroid Biochem 1987;26:197-202

13. Kim WR, Biggins SW, Kremers WK, et al. Hyponatremia and mortality among patients on the liver-transplant waiting list.NEJM, 2008 ;359:1018-1026.

14. Beishuizen A, Thijs LG. Relative adrenal insufficiency in intensive care: an identifiable problem requiring treatment? Best Pract Res Clin Endocrinol Metab 2001;15:513-531

15. Shilov JI, Orlova EG. Role of adrenergic mechanisms in regulation of phagocytic cell 
functions in acute stress response. Immunol Lett 2003; 86:229-233.

16. Moreau R, Gine`s P, Jalan R et al. Acute-onchronic liver failure is a distinct syndrome developing in patients with acute decompensation of cirrosis. Gastroenterology 2013.

17. easl.eu/publications/clinical-practice-guidelines

18. Surviving_Sepsis_Campaign_International_Gui delines 